\title{
Electrodeposition of Palladium Coatings from Iminodiacetate Electrolyte
}

\author{
Valeriy S. Kublanovsky ", Vasiliy N. Nikitenko, Kostiantyn P. Rudenko \\ V. I. Vernadskii Institute of General and Inorganic Chemistry NAS Ukraine, Kyiv, Ukraine \\ Email: *kublan@ukr.net
}

Received August 18, 2013; revised September 25, 2013; accepted October 8, 2013

Copyright (C) 2013 Valeriy S. Kublanovsky et al. This is an open access article distributed under the Creative Commons Attribution License, which permits unrestricted use, distribution, and reproduction in any medium, provided the original work is properly cited.

\begin{abstract}
The ionic composition of an iminodiacetate electrolyte as a function of solution composition and pH has been determined. The kinetic parameters (exchange currents and apparent transfer coefficients) of the electroreduction of a palladium(II) bis-iminodiacetate complex from an electrolyte containing excess ligand have been calculated. It has been shown that the rate of the electrode process is controlled by the diffusion of reduced ions to the electrode surface and by the electron-transfer reaction. The possibility of using iminodiacetate electrolyte for palladium plating for the deposition of fine-crystalline adherent and ductile palladium coatings has been examined.
\end{abstract}

Keywords: Palladium; Iminodiacetate; Complex Compounds; Electrodeposition; Palladium Coatings

\section{Introduction}

The high catalytic activity of palladium, the unique physicochemical and functional properties of its coatings (corrosion resistance in aggressive media, mechanical and electrical erosion wear resistance, high reflectivity, low specific and junction resistance, etc.) [1,2] make them practically indispensable in many industries.

Taking into account the high cost of palladium, the replacement of the monolithic (compact) metal by its functional plated coatings is very expedient.

In microelectronics, electrolytes based on complexones are widely used for the deposition of functional nanocrystalline palladium coatings since they are nontoxic, stable and easily recoverable. Complexones, which are polydentate ligands of acidic type, have a pronounced ability for compatibility with other ligands in the same coordination sphere of mixed-ligand complex and for the retardation of the electrode process or its individual stages; this makes it possible to control the structure and hence the properties of deposited coatings by means of appropriate electrode stages [3].

The practical use of complexonate electrolytes for palladium plating is impossible without reliable information on the ionic composition of the electrolyte, the composition of electrochemically active complexes, the nature of rate-determining steps, the kinetics and mecha-

*Corresponding author. nism of the process.

The aim of this work is to examine the possibility of using the complexonate system $\left[\mathrm{PdL}_{2}\right]^{2-}-\mathrm{H}_{2} \mathrm{~L}-\mathrm{NaClO}_{4}$ $\mathrm{H}_{2} \mathrm{O}$, whether $\mathrm{L}^{2-}$ is anion iminodiacetic acid, in microelectronics to obtain fine-crystalline, adherent, ductile palladium coatings.

\section{Experimental Procedure}

Palladium (II) iminodiacetate complexes were synthesized from palladium(II) chloride by the procedure reported in [4] and identified by IR spectroscopy and Xray phase analysis [5].

The IR spectra of solid samples of the palladium (II) iminodiacetate complexes $\left[\mathrm{Pd}\left(\mathrm{H}_{2} \mathrm{O}\right)_{2} \mathrm{~L}\right]$ and $\left[\mathrm{PdL}_{2}\right]^{2-}$ were recorded in the range $4000-250 \mathrm{~cm}^{-1}$ on a SPECORD-80 M (UR-20) device. The X-ray phase analysis (XPA) was performed on a DRON-2 UM setup with $\mathrm{Cu} K_{\alpha}$ radiation. The recording was performed at the voltage $U=30 \mathrm{kV}$ and the current $\mathrm{I}=20 \mathrm{~mA}$ in the discrete mode. After each $3 \mathrm{~s}$, the sample was rotated by the angle $\Delta 2 \Theta=0.04$ and irradiated.

The palladium plating electrolyte was prepared by dissolving a synthesized palladium(II) bis-iminodiacetate complex in a $1 \mathrm{M} \mathrm{NaClO}_{4}$ solution in the presence of 100 -fold complex one excess. As a result, a palladium plating electrolyte of the composition $\left(\mathrm{mol} \cdot \mathrm{l}^{-1}\right):\left[\mathrm{PdL}_{2}\right]^{2-}$ $\left(5.11 \times 10^{-4}\right),\left[\mathrm{H}_{2} \mathrm{~L}\right]\left(5.11 \times 10^{-2}\right), \mathrm{NaClO}_{4}(1.0)$ has been 
obtained.

The current-potential $E-j$ curves of palladium(II) electroreduction from an iminodiacetate electrolyte were measured using a PI-50.1.1 potentiostat and a PR-8 programmer at a potential scan rate of $1-20 \mathrm{mV} \cdot \mathrm{s}^{-1}$ and recorded with an N 307/1 X-Y potentiometer. The experiments were made in a YaSE-2 thermostatted electrolytic cell under argon in a temperature range of (26 $60) \pm 0.1^{\circ} \mathrm{C}$. The working electrode was a palladium plate of $2.64 \mathrm{~cm}^{2}$ area. A platinum wire sealed in glass was used as the auxiliary electrode. All measurements of potentials were made with respect to a silver-chloride reference electrode.

Before electrodepositing palladium coatings, the surface of the samples on which palladium was deposited was subjected to commonly used preparation. The samples were degreased with soda and Vienna lime, etched for $1-2 \mathrm{~s}$ in a hydrochloric acid solution $\left(150 \mathrm{~g} \cdot \mathrm{l}^{-1}\right)$, washed with distilled water, activated for $1-2 \mathrm{~s}$ in a sulfuric acid solution $\left(50 \mathrm{~g} \cdot \mathrm{l}^{-1}\right)$ and washed again with distilled water.

The palladium coatings were tested for ductility by reversed bending with fracture (bending of specimen through $180^{\circ}$ sequentially on two sides with pressing down of the bend and subsequent smoothing out till the appearance of crack) [6]. The appearance of crack was monitored by means of an XJL-17 AT metallographic microscope with $300 \times$ magnification.

The morphology of palladium deposits was studied on a JEOL SUPERPROBE 733 scanning electron microscope with X-ray microanalyzer at an accelerating voltage of $25 \mathrm{kV}$ at $3000 \times$ magnification.

\section{Results and Discussion}

The IR spectra of solid samples and the results of an $\mathrm{X}$-ray phase analysis (XPA) of the synthesized palladium(II) iminodiacetate complexes are shown in Figures $\mathbf{1}$ and $\mathbf{2}$ respectively.

Based on possible equilibria occurring in iminodiacetate electrolyte (Table 1) and their constants [7], where $k$ is the stepwise formation constant, and $K$ is the overall formation constant of palladium(II) iminodiacetate complexes and protonated forms of ligand, the distribution of ionic forms of palladium(II) as a function of $[\mathrm{L}]^{2-}$ equilibrium concentration and solution $\mathrm{pH}$ has been calculated with allowance for material balance on palladium(II) and ligand ions [5].

A diagram of distribution of ionic forms of palladium (II) and ligand in an iminodiacetate electrolyte as a function of the logarithm of ligand equilibrium concentration and $\mathrm{pH}$ in the bulk solution is shown in Figure 2.

As is seen from Figure 2(b), the main forms of existence of palladium(II) and ligand ions in slightly acid iminodiacetate electrolyte $(\mathrm{pH} 3.8)$ are the complexes
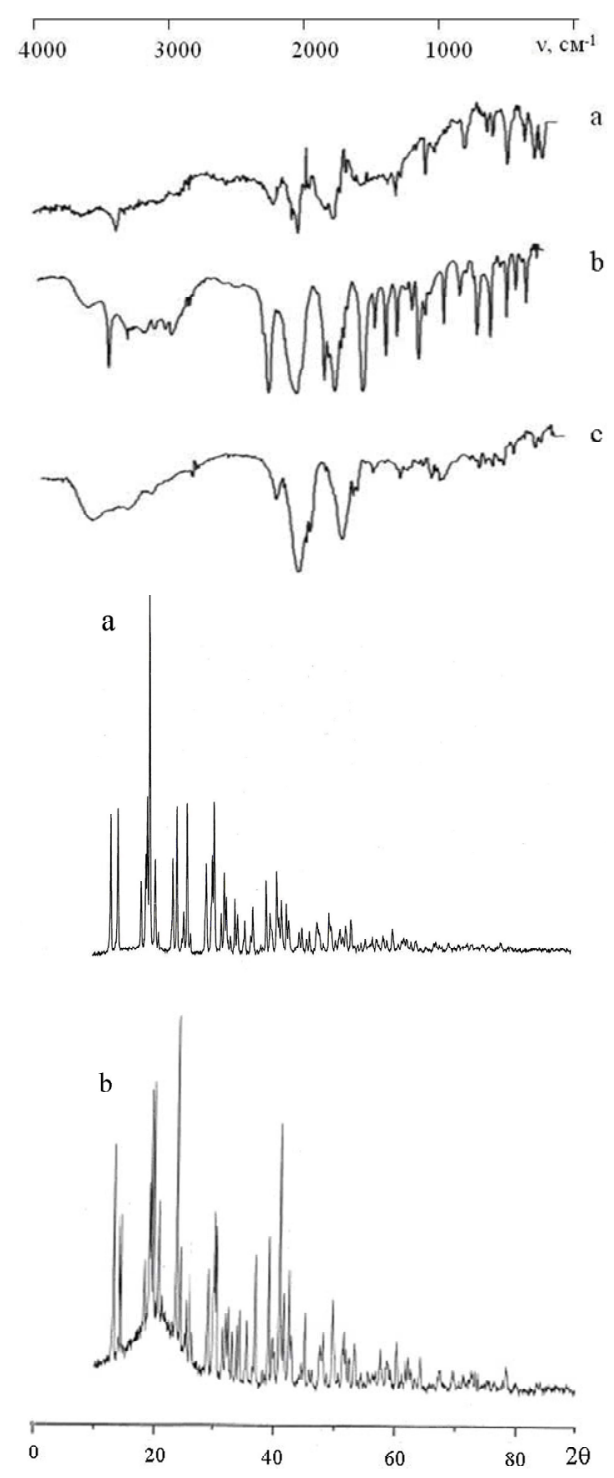

Figure 1. (a): IR spectra of iminodiacetic acid $\left(\mathrm{H}_{2} \mathrm{~L},(\mathrm{a})\right)$, the complexes $\left[\mathrm{Pd}\left(\mathrm{H}_{2} \mathrm{O}\right)_{2} \mathrm{~L}\right](\mathrm{b})$ and $\left[\mathrm{PdL}_{2}\right]^{2-}$ (c) synthesized. (b): $\mathrm{X}$-ray diagrams of the complexes $\left[\mathrm{Pd}\left(\mathrm{H}_{2} \mathrm{O}\right)_{2} \mathrm{~L}\right]$ (a) and $\left[\mathrm{PdL}_{2}\right]^{2-}$ (b) synthesized.

$\left[\mathrm{Pd}\left(\mathrm{H}_{2} \mathrm{O}\right)_{2} \mathrm{~L}\right]$ and $\left[\mathrm{PdL}_{2}\right]^{2-}$ and the protoated form of ligand [HL] respectively [5].

To study the kinetics of the electroreduction of palladium(II) from iminodiacetate electrolyte, stationary (1 $\left.\mathrm{mV} \cdot \mathrm{s}^{-1}\right)$ and nonstationary $\left(2-20 \mathrm{mV} \cdot \mathrm{s}^{-1}\right) \Delta E-j$ curves have been measured (Figure 3).

An analysis of nonstationary $\Delta E-j$ curves (Figure 3(a)), constructed in the $j_{\mathrm{p}}-v^{1 / 2}$ coordinates [8], showed that as follows from Figure 4, the plot of $j_{p}\left(v^{1 / 2}\right)$ is a straight line and is extrapolated to the origin of coordinates, indicating the limiting current of palladium(II) reduction from iminodiacetate electrolyte to be of diffusion nature [5].

The kinetic parameters of palladium(II) electroreduc- 


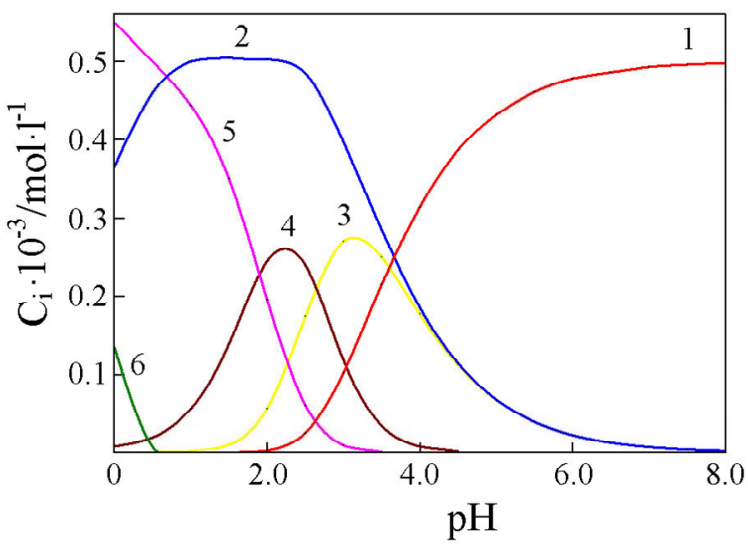

(a)

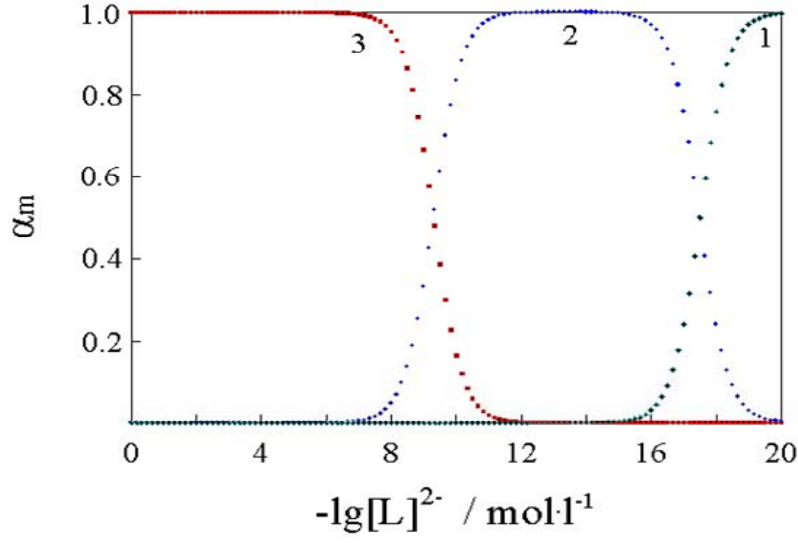

(b)

Figure 2. (a): Distribution of complex forms of palladium(II) in an iminodiacetate electrolyte as a function of the logarithm of ligand equilibrium concentration: $(\diamond-1)\left[\mathrm{Pd}\left(\mathrm{H}_{2} \mathrm{O}\right)_{4}\right]^{2+},(\bullet-2)\left[\mathrm{Pd}\left(\mathrm{H}_{2} \mathrm{O}\right)_{2} \mathrm{~L}\right],(\square-3)\left[\mathrm{PdL}_{2}\right]^{2-}$. (b): Distribution of ionic forms of palladium(II) and ligand in an iminodiacetate electrolyte as a function of solution $\mathrm{pH}$ at the ratio $\mathrm{C}_{\mathrm{Pd}^{2+}} \mathrm{C}_{\mathrm{L}}{ }^{2-}=1: 2$. $(1)$ $\left[\mathrm{PdL}_{2}\right]^{2-},(2)\left[\mathrm{Pd}\left(\mathrm{H}_{2} \mathrm{O}\right)_{2} \mathrm{~L}\right],(3)[\mathrm{HL}]^{-},(4)\left[\mathrm{H}_{2} \mathrm{~L}\right],(5)\left[\mathrm{H}_{3} \mathrm{~L}\right]^{+},(6)\left[\mathrm{Pd}\left(\mathrm{H}_{2} \mathrm{O}\right)_{4}\right]^{2+}$.

Table 1. Chemical equilibria occurring in an iminodiacetate electrolyte for palladium plating.

\begin{tabular}{cccc}
\hline Equilibrium & & $k^{*}$ & $K^{* *}$ \\
\hline $\mathrm{Pd}\left(\mathrm{H}_{2} \mathrm{O}\right)_{4}{ }^{2+}+\mathrm{L}^{2-} \leftrightarrow \mathrm{Pd}\left(\mathrm{H}_{2} \mathrm{O}\right)_{2} \mathrm{~L}$ & $(1)$ & $3.16 \cdot 10^{17}$ & $3.16 \cdot 10^{17}$ \\
$\mathrm{Pd}\left(\mathrm{H}_{2} \mathrm{O}\right)_{2} \mathrm{~L}+\mathrm{L}^{2-} \leftrightarrow \mathrm{PdL}_{2}{ }^{2-}$ & $(2)$ & $2.00 \cdot 10^{9}$ & $6.31 \cdot 10^{26}$ \\
$\mathrm{~L}^{2-}+\mathrm{H}^{+} \leftrightarrow \mathrm{HL}^{-}$ & $(3)$ & $2.09 \cdot 10^{9}$ & $2.09 \cdot 10^{9}$ \\
$\mathrm{HL}^{-}+\mathrm{H}^{+} \leftrightarrow \mathrm{H}_{2} \mathrm{~L}$ & $(4)$ & $4.37 \cdot 10^{2}$ & $9.12 \cdot 10^{11}$ \\
$\mathrm{H}_{2} \mathrm{~L}+\mathrm{H}^{+} \leftrightarrow \mathrm{H}_{3} \mathrm{~L}^{+}$ & $(5)$ & $7.94 \cdot 10^{1}$ & $7.24 \cdot 10^{13}$ \\
\hline
\end{tabular}

${ }^{*} k$ is step formation constants of palladium(II) glycinate complexes and protonated ligand species. ${ }^{* *} K$ is overall formation constants of palladium(II) glycinate complexes and protonated ligand species.

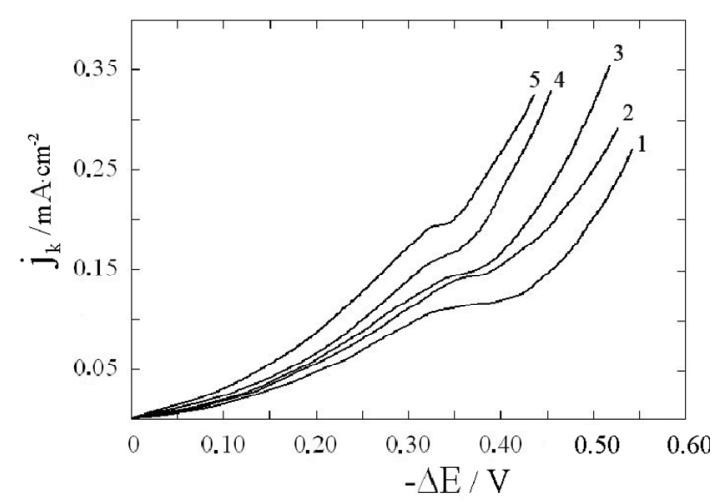

(a)

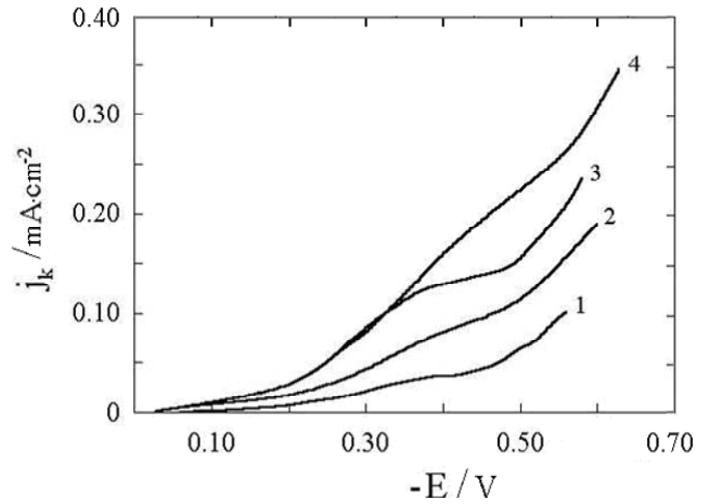

(b)

Figure 3. (a): Polarization curves of palladium(II) reduction from an iminodiacetate electrolyte containing $\left(\mathrm{mol}^{-1} \mathrm{I}^{-1}\right):[\mathrm{PdL}]^{2-}$ $\left(5.11 \times 10^{-4}\right), \mathrm{H}_{2} \mathrm{~L}\left(5.11 \times 10^{-2}\right), \mathrm{NaClO}_{4}(1.0), \mathrm{pH} 3.8$ at $26^{\circ} \mathrm{C}$ and potential scan rate $\left(\mathrm{mV} \cdot \mathrm{s}^{-1}\right): 1.0(1), 5.0(2), 10(3), 20(4) .(\mathrm{b}):$ Polarization curves of palladium(II) reduction from an iminodiacetate electrolyte containing $\left(\mathrm{mol}^{-1} \mathrm{l}^{-1}\right):\left[\mathrm{PdL}_{2}\right]^{2-}\left(5.11 \times 10^{-4}\right)$, $\mathrm{H}_{2} \mathrm{~L}\left(5.11 \times 10^{-2}\right), \mathrm{NaClO}_{4}(1.0), \mathrm{pH} 3.8$ at a potential scan rate of $1 \mathrm{mV} \cdot \mathrm{s}^{-1}$ and temperature $\left({ }^{\circ} \mathrm{C}\right): 26(1), 35(2), 40(3), 50(4)$, 60 (5).

tion from an iminodiacetate electrolyte, determined from stationary $E-j$ curves (Figure 3(b)), constructed in the $\Delta E-\lg \left[\left(j \cdot j_{\mathrm{d}}\right) /\left(j_{\mathrm{d}}-j\right)\right]$ coordinates, i.e. with allowance for the effect of concentration polarization on electrode kinetics, are listed in Table 2.
The results of calculations show that the coordination number of $\left[\mathrm{PdL}_{2}\right]^{2-2 \mathrm{n}}$ complex ions, which predominate in the bulk of iminodiacetate electrolyte containing a 100fold excess of free ligand, at $\mathrm{pH} 3.8$ is 2 .

It was shown earlier [5] that the electron-transfer reac- 
Table 2. Kinetic parameters of palladium(II) electroreduction from an iminodiacetate electrolyte $\left(\mathrm{CPd}^{2+} / \mathrm{CL}^{2-}=1: 100, \mathrm{pH} \mathrm{3.8}\right)$.

\begin{tabular}{ccccccc}
\hline $\mathrm{T}\left({ }^{\circ} \mathrm{C}\right)$ & $\begin{array}{c}-\lg j_{\mathrm{d}} \\
\left(\mathrm{mA} \cdot \mathrm{m}^{-2}\right)\end{array}$ & $\begin{array}{c}\mathrm{D}_{\mathrm{i}} \cdot 10^{5} \\
\left(\mathrm{~cm}^{2} \cdot \mathrm{s}^{-1}\right)\end{array}$ & $b_{\mathrm{k}}(\mathrm{V})$ & $\alpha^{\prime}$ & $\begin{array}{c}-\lg j_{\mathrm{o}} \text { wb(*) } \\
\left(\mathrm{mA} \cdot \mathrm{cm}^{-2}\right)\end{array}$ & $\begin{array}{c}-\lg j_{\mathrm{o}} \text { wa(**) } \\
\left(\mathrm{mA} \cdot \mathrm{cm}^{-2}\right)\end{array}$ \\
\hline 26 & 1.47 & 0.69 & 0.136 & 0.42 & 3.47 & 3.19 \\
35 & 1.30 & 1.01 & 0.146 & 0.41 & 3.28 & 2.94 \\
40 & 1.26 & 1.12 & 0.151 & 0.41 & 3.14 & 2.71 \\
50 & 1.21 & 1.26 & 0.157 & 0.40 & 3.04 & 2.47 \\
60 & 1.09 & 1.54 & 0.164 & 0.40 & 2.25 \\
\hline
\end{tabular}

$j_{\mathrm{o}}{ }^{\mathrm{wb}(*)}$ _exchange current density of barrierless palladium(II) discharge; $j_{\mathrm{o}}{ }^{\text {wa( }(* *)}$ _exchange current density of activationless palladium(II) discharge.

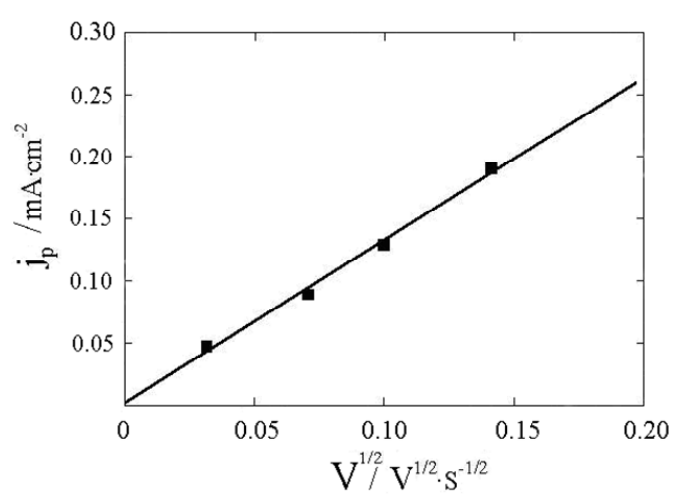

Figure 4. Dependence of limiting cathode current on square root from sweep rate in an iminodiacetate electrolyte containing $\left.\left(\mathrm{mol}^{-1}\right)^{-1}\right):\left[\mathrm{PdL}_{2}\right]^{2-}\left(5.11 \times \mathbf{1 0}^{-4}\right), \mathrm{H}_{2} \mathrm{~L}\left(5.11 \times \mathbf{1 0}^{-2}\right)$, $\mathrm{NaClO}_{4}(1.0)$, $\mathrm{pH} \mathrm{3.8,} 26^{\circ} \mathrm{C}$.

tion in palladium(II) reduction from iminodiacetate electrolyte containing a 100-fold excess of free ligand at $\mathrm{pH}$ 3.8 involves $\left[\mathrm{PdL}_{2}\right]^{2-}$ complexes. The mechanism of palladium(II) electroreduction from iminodiacetate electrolyte was proposed in Refs [4,5].

With allowance for ionic composition, mass transfer, the kinetics and mechanism of palladium(II) electroreduction from iminodiacetate electrolyte and the nature of the rate-determining step, the possibility of using this complexonate electrolyte for the deposition of highquality fine-crystalline and adherent functional palladium coatings has been examined.

The electrolyte under investigation contained at the bottom of the electrolytic cell excess palladium(II) complex in order that constant palladium ion concentration might be maintained during the experiment. The palladium(II) ion concentration in the electrolyte for palladium plating was not over $6 \times 10^{-4} \mathrm{~mol} \cdot \mathrm{l}^{-1}$ at the 50 -fold excess of iminodiacetate due to the low solubility of palladium(II) iminodiacetate complex.

Palladium coatings were deposited from a prepared iminodiacetate electrolyte containing $\left(\mathrm{mol} \cdot \mathrm{l}^{-1}\right):\left[\mathrm{PdL}_{\mathrm{n}}\right]^{2-}$ $\left(6.0 \times 10^{-4}\right),\left[\mathrm{H}_{2} \mathrm{~L}\right]\left(3.0 \times 10^{-2}\right), \mathrm{NaClO}_{4}(1.0)$ at $23^{\circ} \mathrm{C}, \mathrm{pH}$ $4.2-4.3$ and a current density of $0.03 \mathrm{~A} \cdot \mathrm{dm}^{-2}$. Palladium was deposited on one side of a $20 \mu \mathrm{m}$ thick polyethylene film chemically coated with a $1-2 \mu \mathrm{m}$ thick nickel layer. The nickel layer on the other side of the polyethylene film was previously stripped with a concentrated hydrochloric acid solution. The electrolysis time was calculated by the Faraday law with allowance for the current yield of metal, which was $75 \%$ - $99 \%$ depending on coating thickness, and monitored by cathode weight increase. A platinum plate was used as the anode.

Micrographs of the structure of palladium coatings electrodeposited from the iminodiacetate electrolyte under investigation as a function of coating thickness $(0.5$ $\mu \mathrm{m}$ and $0.75 \mu \mathrm{m}$ ) are shown in Figure 5. On the basis of morphological data (Figure 5), the dependence of the particle size distribution of palladium coatings, deposited from an iminodiacetate electrolyte, on an electrolessnickel-coated polyethylene film was studied.

The dependence of crystallite size distribution is shown in Figure 6, from which it is seen that in $0.5 \mu \mathrm{m}$ thick palladium coatings (Figure 6(a)), $0.08-0.58 \mu \mathrm{m}$ crystallites predominate, though $0.08-1.20 \mu \mathrm{m}$ crystallites are also present. Palladium coatings $0.75 \mu \mathrm{m}$ in thickness (Figure 6(b)) consist of $0.25-1.70 \mu \mathrm{m}$ crystallites, but $0.60-1.20 \mu \mathrm{m}$ crystallites predominate.

It follows from Figure 6 that the formation of palladium electrodeposits on a polyethylene film precoated with electroless nickel begins with the formation on the substrate surface of crystallizing nuclei, from which crystallites of definite size grow during the cathodic deposition of the metal, which enlarge with the growth of the electrodeposit.

The ductility tests of palladium coatings deposited from an iminodiacetate electrolyte were carried out for thicknesses of $0.50 \mu \mathrm{m}$ and $0.75 \mu \mathrm{m}$. The 0.50 and 0.75 $\mu \mathrm{m}$ thick palladium coatings electrodeposited from an iminodiacetate electrolyte withstand 4 and 5 bendings respectively.

\section{Conclusions}

Allowing for ionic composition, the kinetics and mechanism of the electroreduction of a palladium(II) bis-iminodiacetate complex and the nature of the rate-determining step of the process, it has been shown that iminodiacetate electrolyte can be used for the deposition of fine-crystalline adherent and very ductile palladium coatings. 

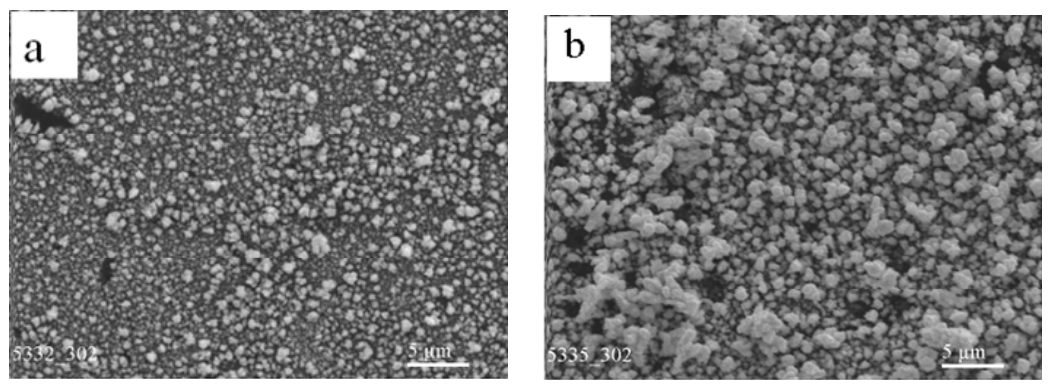

Figure 5. Micrographs of palladium deposits $0.5 \mu \mathrm{m}$ (a) and $0.75 \mu \mathrm{m}$ (b) in thickness obtained from an iminodiacetate electrolyte containing $\left(\mathrm{mol}^{-1} \mathrm{I}^{-1}\right)$ : $\left[\mathrm{PdL}_{2}\right]^{2-}\left(6.0 \times 10^{-4}\right), \mathrm{H}_{2} \mathrm{~L}\left(3.0 \times 10^{-2}\right), \mathrm{NaClO}_{4}(1.0), \mathrm{pH} 4.3$ on a nickel-plated polyethylene film at a current density of $0.03 \mathrm{~A} \cdot \mathrm{dm}^{-2}$.
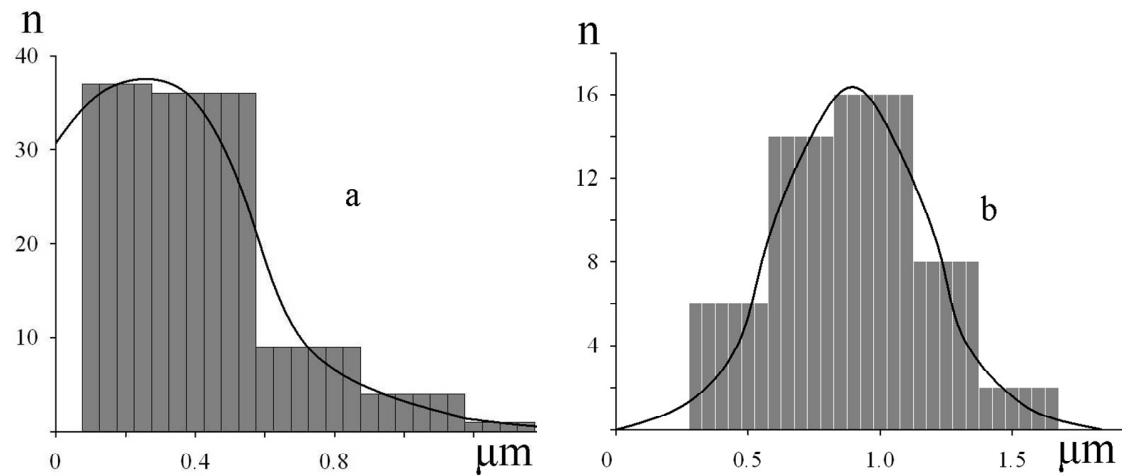

Figure 6. Size distribution of palladium particles deposited from an iminodiacetate electrolyte containing $\left(\mathrm{mol}^{-1} \cdot \mathrm{I}^{-1}\right):\left[\mathrm{PdL}_{2}\right]^{2-}$ $\left(6.0 \times 10^{-4}\right), \mathrm{H}_{2} \mathrm{~L}\left(3.0 \times 10^{-2}\right), \mathrm{NaClO}_{4}(1.0), \mathrm{pH} 4.3$ on a nickel-plated polyethylene film at a current density of $0.03 \mathrm{~A} \cdot \mathrm{dm}^{-2}$; deposit thickness $0.5 \mu \mathrm{m}$ (a) and $0.75 \mu \mathrm{m}(\mathrm{b})$.

The advantages of the proposed complexonate electrolyte are its nontoxicity (environmental safety), stability during operation, ease of recovery and relative cheapness in comparison with other palladium plating methods.

\section{REFERENCES}

[1] N. V. Korovin, "Corrosion and Electrochemical Properties of Palladium," Metallurgiya, Moscow, 1976.

[2] G. K. Burkat, "Electrodeposition of Precious Metals," Politekhnika, St. Petersburg, 2009.

[3] V. S. Kyblanovsky and V. N. Nikitenko, "Electrochemical Properties of Palladium(II) Trans- and cis-Diglycinate Complexes," Electrochimica Acta, Vol. 56, No. 5, 2011, pp. 2110-2115. http://dx.doi.org/10.1016/j.electacta.2010.11.028

[4] Ya. V. Russkikh, V. I. Kravtsov, "Kinetics and Mechanism of the Electroreduction of Palladium (II) Bis-Iminodiacetate Complexes at the Dropping Mercury-Elec- trode," Russian Journal of Electrochemistry, Vol. 33, No. 10, 1997, p. 1153

[5] V. S. Kublanovsky, V. N. Nikitenko and K. P. Rudenko, "Electroreduction of Bis-Iminodiacetate Complexes of Palladium (II) on a Palladium Electrode," Ukrainskii Khimicheskii Zhurnal, Vol. 75, No. 7, 2009, p. 56.

[6] V. S. Kublanovsky, V. N. Nikitenko and N. V. Chornen$\mathrm{ka}$, "Kinetics of the Electrodeposition and Properties of Palladium Coatings from Aminoacetate Electrolyte," Physicochemical Mechanics of Materials, No. 5, 2006, p. 620.

[7] G. Anderegg and S. C. Malik, "Komplexone XLVII. The Stability of Palladium(II) Complexes with Aminopolycarboxylate Anions," Helvetica Chimica Acta, Vol. 59, No. 5, 1976, pp. 1498-1511. http://dx.doi.org/10.1002/hlca.19760590511

[8] A. J. Bard, L. R. Faulkner, "Electrochemical Methods. Fundamental and Applications," Jons Willey \& Sons, Inc., New York, 2001. 